\title{
ACÚMULO E DISTRIBUIÇÃO DE MACRONUTRIENTES EM DOIS HÍBRIDOS DUPLOS DE MILHO, EM FUNÇÃO DA DISPONIBILIDADE DE ÁGUA NO SOLO
}

\author{
VILMA MARQUES FERREIRA, PAULO CÉSAR MAGALHÃES²; FREDERICO O. M. DURÃES², \\ CARLOS ALBERTO VASCONCELLOS² ${ }^{2}$ JOÃO CORREIA DE ARAUJO NETO ${ }^{1}$
}

${ }^{1}$ Profs. Adjuntos, Drs., Centro de Ciências Agrárias UFAL, BR 104 Norte km 85, CEP 57100-000, Rio Largo, AL. Autor para correspondência: vilmaferreira@ceca.ufal.br

${ }^{2}$ Pesquisadores, Drs., Embrapa Milho e Sorgo, C. P. 151, CEP 35900-970, Sete Lagoas, MG, pcesar@cnpms.embrapa.br

Revista Brasileira de Milho e Sorgo, v.7, n.1, p. 1-17, 2008

RESUMO - A quantidade de nutrientes presente nos tecidos vegetais de uma determinada espécie, em um dado momento, é função da interação das condições ambientais com o genótipo e é de importância ecológica e econômica, pois permite a otimização do uso dos insumos e de diferentes manejos importantes na sustentabilidade do sistema produtivo. Neste trabalho, foram quantificados os macronutrientes nos diferentes órgãos de plantas de dois híbridos duplos de milho (BRS 2121 e BR 205) cultivados em campo, submetidos a quatro épocas (dez dias antes ou 15, 30 e 50 dias após a floração) de supressão da irrigação e três tipos de parcelamento da adubação de cobertura de $\mathrm{N}$ e $\mathrm{K}\left(10 \mathrm{~kg}\right.$ de N ha-1 $+90 \mathrm{~kg}_{\text {de }} \mathrm{K}_{2} \mathrm{O} \mathrm{ha}^{-1}$ no plantio e $120 \mathrm{~kg}$ de $\mathrm{N} \mathrm{ha}^{-1}$ no estádio V8; $10 \mathrm{~kg}$ de $\mathrm{N} \mathrm{ha}^{-1}+45 \mathrm{~kg}$ de $\mathrm{K}_{2} \mathrm{O}$ ha $^{-1}$ no plantio e $45 \mathrm{~kg} \mathrm{ha}^{-1}$ de $\mathrm{K}_{2} \mathrm{O}+$

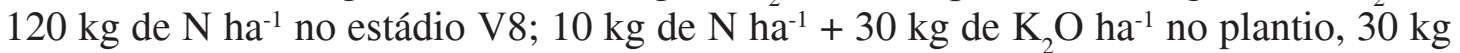
$\mathrm{ha}^{-1}$ de $\mathrm{K}_{2} \mathrm{O}+60 \mathrm{~kg}$ de $\mathrm{N}$ ha-1 no estádio V8 e $30 \mathrm{~kg} \mathrm{ha}^{-1}$ de $\mathrm{K}_{2} \mathrm{O}+60 \mathrm{~kg} \mathrm{de} \mathrm{N} \mathrm{ha}^{-1}$ no estádio V12), bem como em plantas jovens dos mesmos híbridos, cultivadas em casade-vegetação, sob quatro regimes hídricos: irrigação diária ou a cada três, cinco ou sete dias. Os resultados mostraram que, em campo, a resposta ao deficit hídrico variou de acordo com o nutriente e o órgão analisado. Em casa-de-vegetação houve tendência de concentração dos nutrientes nos tecidos em resposta ao déficit hídrico.

Palavras-chave: Zea mays, estresse hídrico, nutrição mineral.

\section{CONCENTRATION AND PARTITIONING OF MACRO NUTRIENTS IN TWO MAIZE GENOTYPES AS RELATED TO SOIL WATER AVAILABILITY}

\begin{abstract}
The amount of nutrients present in crop tissue of a certain species, at certain time, is a result of the interaction between environmental conditions and genotype. This interaction is economically and ecologically important since permits the best use of fertilizers as well as different crop management which are essential for the sustainability of the productive system. In this paper, macronutrients were quantified in different parts of two adult maize plant genotypes (BRS 2121 and BR 205), which were evaluated at field conditions. The treatments imposed in this research were four water regimes (irrigation suppression at 10 days before blooming and 15, 30 and 50
\end{abstract}


days after blooming) and three types of fertilizer side dress application of $\mathrm{N}$ and $\mathrm{K}$ $\left(10 \mathrm{~kg} \mathrm{~N} \mathrm{ha}^{-1}+90 \mathrm{~kg} \mathrm{~K}_{2} \mathrm{O} \mathrm{ha} \mathrm{h}^{-1}\right.$ at planting and $120 \mathrm{~kg} \mathrm{~N} \mathrm{ha}^{-1}$ at V8 stage; $10 \mathrm{~kg} \mathrm{~N}$ $\mathrm{ha}^{-1}+45 \mathrm{~kg} \mathrm{~K}_{2} \mathrm{O} \mathrm{ha}^{-1}$ at planting and $45 \mathrm{~kg} \mathrm{~K}_{2} \mathrm{O} \mathrm{ha}{ }^{-1}+120 \mathrm{~kg} \mathrm{~N}^{-1}$ at V8 stage; 10 $\mathrm{kg} \mathrm{N} \mathrm{ha}^{-1}+30 \mathrm{~kg} \mathrm{~K}_{2} \mathrm{O} \mathrm{ha}^{-1}$ at planting, $30 \mathrm{~kg} \mathrm{~K}_{2} \mathrm{O} \mathrm{ha}^{-1}+60 \mathrm{~kg} \mathrm{~N} \mathrm{ha}^{-1}$ at V8 stage and $30 \mathrm{~kg} \mathrm{~K}_{2} \mathrm{O} \mathrm{ha}^{1}+60 \mathrm{~kg} \mathrm{~N}^{-1}$ at V12 growth stage). This experiment was also carried out at greenhouse conditions on young plants of the same genotypes under four water regimes, daily irrigation or each three, five or seven days. The results showed that, at field conditions, the behavior of maize plants under water deficit varied according to nutrient and part of the plant analyzed, whereas at greenhouse conditions there was a tendency of nutrients concentration in crop tissue due to water deficit.

Key words: Zea mays, water stress, mineral nutrition.

Fatores ambientais e genótipo interferem na absorção, translocação, acúmulo e utilização de nutrientes minerais pelas plantas. Dentre os fatores ambientais, a disponibilidade de água é muito importante, visto ser o veículo de condução dos elementos até a interface soloraiz e no xilema, além de interferir na fisiologia da planta, na dinâmica de absorção e utilização dos nutrientes. $\mathrm{O}$ conhecimento de como e quanto os elementos presentes nos diferentes tecidos da planta são afetados é de importância ecológica (reciclagem dos nutrientes) e econômica (influência na nutrição dos seres que se alimentam de plantas e economia dos insumos).

Quando a disponibilidade de água no solo é baixa, todos os íons tornam-se menos móveis, porque o ar substitui a água nos espaços porosos entre as partículas do solo, aumentando a tortuosidade e a força de retenção iônica pelos colóides do solo. Esses efeitos sobre a mobilidade dos nutrientes são importantes mesmo em situações em que o conteúdo de água tem pouco efeito sobre as relações hídricas, resultando em redução na absorção dos mesmos (Chapin, 1991). Por outro lado, quando o crescimento das plantas é mais afetado do que a absorção dos nutrientes, a concentração destes, nos tecidos vegetais, pode aumentar.

Em milho, a deficiência hídrica reduz o potencial produtivo da cultura, especialmente quando ocorre durante o período reprodutivo (Bergamaschi et al., 2007). Entretanto, o efeito desse estresse sobre o acúmulo e a partição dos nutrientes não tem sido bem quantificado, especialmente nos materiais tropicais.

Dentre os estudos realizados em regiões de clima temperado, algumas generalizações podem ser feitas. Nesse sentido, Schussler e Westgate (1991a) afirmam que, quando o estresse hídrico reduz drasticamente a produção de grãos em plantas de milho, o $\mathrm{N}$ pode se acumular nos grãos remanescentes, promovendo aumento na sua concentração. Sendo assim, a disponibilidade desse nutriente não é considerada um fator limitante para a produção sob tais condições.

O K é amplamente citado na literatura como um importante contribuinte para o ajustamento osmótico que pode ocorrer sob condições de deficiência hídrica (Morgan, 1984; Cutler e Rains, 1978; Premachandra et al., 1989; 1990). 
Marschner (1995) relata que é comum ocorrer redução nos teores de cálcio em tecidos vegetais quando há limitação da disponibilidade hídrica, uma vez que a quantidade desse elemento em um determinado órgão da planta depende grandemente da corrente transpiratória, devido ao seu transporte essencialmente xilemático. Por outro lado, Pitman (1981) afirma que há aumento da concentração relativa de cátions, incluindo o $\mathrm{Ca}$, na solução do solo, quando há redução de umidade, que pode, conseqüentemente, aumentar a absorção desse nutriente pelas plantas.

Neste trabalho, objetivou-se determinar a concentração dos macronutrientes em tecidos vegetativos e reprodutivos de plantas adultas, cultivadas em campo, e em tecidos vegetativos de plantas cultivadas em casa-de-vegetação, de dois híbridos de milho (Zea mays L.) submetidos a déficit hídrico.

\section{Material e Métodos}

Foram conduzidos dois experimentos, em área da Embrapa Milho e Sorgo, no município de Sete Lagoas, MG. De acordo com a classificação climática de Köppen, o clima é do tipo Aw. O solo utilizado foi um Latossolo Vermelho, distrófico, álico, fase cerrado, segundo classificação de Panoso et al. (2002). O primeiro experimento foi conduzido em campo e o segundo, em casade-vegetação, a qual apresentava cobertura plástica e sistema automático de umidificação e ventilação.

Foram utilizados os híbridos duplos de milho BRS 2121 e BR 205, ambos desenvolvidos pela Embrapa Milho e Sorgo. O BR 205 é de ciclo precoce, considerado tolerante à seca $\mathrm{e}$ ao alumínio. O BRS 2121 é um híbrido duplo, precoce, que apresenta a qualidade protéica dos grãos melhorada (EMBRAPA, 1997).

No experimento de campo, adotou-se o delineamento experimental em blocos casualizados, com três repetições, com parcelas subsubdivididas. As parcelas foram compostas pelos híbridos, as subparcelas pelo parcelamento da adubação e as subsubparcelas pela supressão da irrigação, em esquema $2 \times 3 \times 4$.

A parcela foi composta por seis fileiras de $10 \mathrm{~m}$ lineares, espaçadas entre si $0,9 \mathrm{~m}$, com 50 plantas cada, espaçadas entre si 0,2 $\mathrm{m}$. As duas linhas laterais foram consideradas como bordadura, as duas intermediárias foram utilizadas para amostragens ao longo do experimento e as duas centrais, para coleta de espigas e grãos. Para efeito de área útil, descartou-se $0,5 \mathrm{~m}$ em cada extremidade.

O solo apresentava as seguintes características químicas: $\mathrm{pH}=5,9 ; \mathrm{H}+\mathrm{Al}=4,12$ eq.mg/ $100 \mathrm{cc} ; \mathrm{Al}=0,0$ eq.mg/100cc; $\mathrm{Ca}=3,81$ eq.mg/ $100 \mathrm{cc} ; \mathrm{Mg}=1,09$ eq.mg/100cc; $\mathrm{K}=71,3$ $\mathrm{mg} / \mathrm{kg} ; \mathrm{P}=8,0 \mathrm{mg} / \mathrm{kg}$; teor de matéria orgânica $=3,84 \%$ e saturação por $\mathrm{Al}=0,0 \%$, segundo a análise química (média de nove amostras).

Os níveis de parcelamento da adubação foram assim definidos:

1 - $10 \mathrm{~kg} / \mathrm{ha}$ de $\mathrm{Ne} 90 \mathrm{~kg} / \mathrm{ha}$ de K no plantio e $120 \mathrm{~kg} / \mathrm{ha}$ de $\mathrm{N}$ no estádio V8 (conforme a nomenclatura de Ritchie et al., 1989);

2 - $10 \mathrm{~kg} / \mathrm{ha}$ de $\mathrm{N}$ e $45 \mathrm{~kg} / \mathrm{ha}$ de $\mathrm{K}$ no plantio, $120 \mathrm{~kg} / \mathrm{ha}$ de $\mathrm{N}$ e $45 \mathrm{~kg} / \mathrm{ha}$ de $\mathrm{K}$ no estádio V8;

$3-10 \mathrm{~kg} / \mathrm{ha}$ de $\mathrm{N}$ e $30 \mathrm{~kg} / \mathrm{ha}$ de $\mathrm{K}$ no plantio, $60 \mathrm{~kg} / \mathrm{ha}$ de $\mathrm{N}$ e $30 \mathrm{~kg} / \mathrm{ha}$ de $\mathrm{K}$ no estádio V8 e $60 \mathrm{~kg} / \mathrm{ha}$ de $\mathrm{N}$ e $30 \mathrm{~kg} / \mathrm{ha}$ de $\mathrm{K}$ no estádio V12.

A irrigação foi realizada por meio de aspersores setoriais, sendo a quantidade de água baseada no balanço hídrico do solo, 
considerando-se a evapotranspiração e a precipitação pluvial (cujo total ao longo do experimento foi de aproximadamente $70 \mathrm{~mm}$, concentrada no último mês do experimento), mantendo-se o solo na capacidade de campo. Os tratamentos de supressão da irrigação (SI) foram assim definidos: 1 - SI aos 10 dias antes da floração (DAF), identificada pela presença de encartuchamento; 2 - SI aos 15 dias após floração (DPF); 3 - SI aos 30 DPF; 4 - SI aos 50 $\mathrm{DPF}$, o qual foi considerado como testemunha.

$\mathrm{Na}$ determinação da massa seca das plantas e na quantificação dos macronutrientes nos tecidos vegetativos e nas espigas, aos 35 DPF, foram coletadas três plantas por parcela, as quais foram divididas em folhas, caule, internódios basais à espiga, pendão e espigas, sendo, então, levadas à estufa de circulação forçada de ar, a $70^{\circ} \mathrm{C}$, até peso constante. Após secagem, cada parte da planta foi pesada, para determinação da fitomassa e, em seguida, moída. A extração dos elementos foi realizada de acordo com Sarruge \& Haaq (1974). O N foi quantificado pelo método MacroKjeldahl, o enxofre (S) pelo método da turbidez de sulfato de bário, os demais nutrientes ( $\mathrm{P}, \mathrm{K}, \mathrm{Ca}$ e $\mathrm{Mg}$ ) foram determinados por espectrometria de Emissão Plasma, ICP - modelo Shimadzu 1014. A determinação da concentração dos nutrientes nos grãos foi feita na época da colheita.

Para o experimento de casa-devegetação, foi utilizado o mesmo tipo de solo do experimento anterior (Latossolo Vermelho álico, fase Cerrado), retirado da camada superficial (aproximadamente 20 $\mathrm{cm})$. A adubação de plantio (N, P, K e micronutrientes) foi realizada de acordo com recomendação técnica, baseada nos resultados das análises químicas do solo. Aplicou-se, ainda, carbonato de cálcio puro para correção da acidez. Quando as plantas atingiram o estádio V6, fez-se a primeira adubação nitrogenada de cobertura, utilizando-se uréia como fonte de N. A segunda adubação de cobertura foi realizada no estádio V10.

A semeadura foi feita em vasos contendo 14,3 dm3 de solo, cuja umidade encontrava-se em torno de $22,65 \%$, e que, em sua base, possuía uma camada de $1,5 \mathrm{~kg}$ de brita, utilizada para facilitar a drenagem da água. A emergência das plântulas ocorreu cinco dias após a semeadura (DAS). Aos 12 DAS foi feito o desbaste, deixando-se duas plantas por vaso.

$\mathrm{O}$ delineamento experimental utilizado foi o inteiramente casualizado, sob um esquema fatorial $2 \times 4$, em que os fatores estudados foram híbridos (BRS 2121 e BR 205) e intervalos, em dias, para reposição da água evapotranspirada (Reposição diária $-\mathrm{T}_{1}$, considerada como testemunha; e reposições a cada três $-\mathrm{T}_{3}$, cinco $-\mathrm{T}_{5}$ e sete $-\mathrm{T}_{7}$ dias), com quatro repetições. Cada unidade experimental consistiu de um vaso contendo duas plantas.

Aos 50 dias após a emergência, foi realizada a coleta das plantas, para quantificação dos nutrientes, utilizando a metodologia já descrita. Os resultados obtidos foram submetidos à análise de variância e as médias, comparadas pelo teste de Tukey, ao nível de 5\% de probabilidade.

\section{Resultados e Discussão}

\section{Experimento conduzido em campo}

O parcelamento da adubação de cobertura de $\mathrm{N}$ e K não teve efeito sobre a concentração dos macronutrientes nos diferentes órgãos, como pode ser observado pelos resultados do teste F, apresentados nas Tabelas 1 a 6 . 
Os híbridos diferiram entre si quanto à concentração de $\mathrm{N}$ (Tabela 1) nos tecidos, sendo que o BRS 2121 apresentou concentração superior desse elemento em todos os órgãos. Nas folhas, a supressão da irrigação aos 10 DAF diminuiu significativamente $(\mathrm{p}<0,05)$ a concentração desse nutriente, diferindo das demais épocas de supressão, em ambos os híbridos. Nos internódios basais às espigas, a concentração de $\mathrm{N}$ não diferiu entre os regimes hídricos, no híbrido BRS 2121, enquanto, que no BR 205, a supressão da irrigação aos 10 DAF provocou aumento na concentração de $\mathrm{N}$. Não houve efeito da deficiência hídrica sobre os teores desse nutriente no colmo e no pendão, para os dois híbridos de milho.

Nas espigas, a concentração de $\mathrm{N}$ foi reduzida apenas em um dos híbridos (BRS 2121), quando houve supressão da irrigação aos 10 DAF. Nos grãos, os híbridos apresentaram resposta diferenciada às épocas de supressão da irrigação: no híbrido BRS 2121, houve redução do teor médio de $\mathrm{N}$ com a supressão aos $10 \mathrm{DAF}$, ao passo que a supressão aos 15 e 30 DPF proporcionou aumento na concentração do nutriente; inversamente, no BR 205, houve acúmulo de N com a supressão aos 10 DAF, o qual não diferiu da testemunha e foi superior ao das demais épocas de supressão.

$\mathrm{O}$ teor médio de $\mathrm{N}$ nas folhas, de modo geral, foi inferior ao considerado adequado $(2,75 \%$ a $3,25 \%$, segundo Barber \& Olson 1968), agravando-se com a SI aos 10 DAF, no híbrido BR 205, quando ocorreu a mais baixa concentração do nutriente. Esse fato, porém, pode ser atribuído à época em que foi feita a determinação, durante a formação da espiga, quando está havendo translocação de nutrientes da folha para esse órgão.
Diminuições nos teores foliares de N, em resposta à deficiência hídrica, foram encontradas em diversos experimentos com plantas de milho (Frederick et al. 1990; Schussler \& Westgate, 1991a, 1991b; Westgate, 1994; Schussler \& Westgate, 1994). Tal diminuição pode ser atribuída tanto à inibição na absorção e redução do N como ao aumento na proporção do elemento remobilizado das folhas para os grãos em enchimento (Westgate, 1994)

Os valores da concentração de $\mathrm{N}$ no colmo estão dentro da faixa de ocorrência relatada por Akporhonor et al. (2005), o qual encontrou variação de 0,86 a $0,60 \%$ de $\mathrm{N}$ no colmo de plantas de milho dos 30 aos 60 dias após o plantio, respectivamente.

$\mathrm{O}$ acúmulo de $\mathrm{N}$ ocorrido nos internódios basais à espiga, ocorrido no híbrido BR 205, quando houve maior limitação hídrica, pode ter ocorrido devido à menor quantidade de grãos formados (Ferreira et al., 2000), uma vez, que nesse tratamento, foi reduzida em $98 \%$ em relação à testemunha, e conseqüentemente, o $\mathrm{N}$ disponível para a formação dos grãos permaneceu nos internódios, levando ao acúmulo do nutriente nesse tecido. Nos grãos do mesmo híbrido e condição hídrica, também se observou maior concentração do nutriente (Tabela 1).

Nos pendões, o $\mathrm{N}$ apresentou concentração elevada, semelhante à de folhas, para o híbrido BRS 2121, independente da supressão da irrigação. Provavelmente não houve limitação hídrica para a formação desse órgão, portanto, não afetando o suprimento de N. Além disso, pode-se supor que não houve remobilização de $\mathrm{N}$ destes para as espigas, formadas posteriormente.

A concentração de $\mathrm{P}$ (Tabela 2) nas folhas reduziu-se em ambos os híbridos quando houve supressão da irrigação aos 10 DAF, sendo que, no 
TABELA 1. Concentração de nitrogênio em folhas, internódios basais às espigas, colmo, pendão, espigas e grãos de dois híbridos de milho submetidos a quatro épocas de supressão da irrigação.

\begin{tabular}{|c|c|c|c|c|c|c|c|}
\hline Híbrido & Época de SI & Folhas & Internódios & Colmo & Pendão & Espigas & Grãos \\
\hline & & \multicolumn{6}{|c|}{$\%$} \\
\hline \multirow[t]{5}{*}{ BRS 2121} & $10 \mathrm{DAF}^{1}$ & $2,16 \mathrm{~A}$ & $0,87 \mathrm{~A}$ & $0,81 \mathrm{~A}$ & $2,53 \mathrm{~A}$ & $1,56 \mathrm{~A}$ & $1,77 \mathrm{~A}$ \\
\hline & $15 \mathrm{DPF}^{2}$ & $2,50 \mathrm{~B}$ & $0,87 \mathrm{~A}$ & $0,81 \mathrm{~A}$ & $2,73 \mathrm{~A}$ & $1,90 \mathrm{AB}$ & $1,91 \mathrm{~B}$ \\
\hline & $30 \mathrm{DPF}$ & $2,52 \mathrm{~B}$ & $0,81 \mathrm{~A}$ & $0,80 \mathrm{~A}$ & $2,65 \mathrm{~A}$ & $2,02 \mathrm{~B}$ & $1,93 \mathrm{~B}$ \\
\hline & $50 \mathrm{DPF}$ & $2,56 \mathrm{~B}$ & $0,91 \mathrm{~A}$ & $0,85 \mathrm{~A}$ & $2,50 \mathrm{~A}$ & $1,91 \mathrm{AB}$ & $1,81 \mathrm{C}$ \\
\hline & Média & $2,43 \mathrm{a}$ & $0,86 \mathrm{a}$ & $0,82 \mathrm{a}$ & $2,60 \mathrm{a}$ & $1,85 \mathrm{a}$ & $1,86 \mathrm{a}$ \\
\hline \multirow[t]{5}{*}{ BR 205} & $10 \mathrm{DAF}$ & $1,43 \mathrm{~A}$ & $0,93 \mathrm{~A}$ & $0,74 \mathrm{~A}$ & $1,45 \mathrm{~A}$ & $1,57 \mathrm{~A}$ & $1,69 \mathrm{~A}$ \\
\hline & $15 \mathrm{DPF}$ & $2,44 \mathrm{~B}$ & $0,66 \mathrm{~B}$ & $0,64 \mathrm{~A}$ & $1,47 \mathrm{~A}$ & $1,34 \mathrm{~A}$ & $1,55 \mathrm{~B}$ \\
\hline & $30 \mathrm{DPF}$ & $2,33 \mathrm{~B}$ & $0,74 \mathrm{~B}$ & $0,66 \mathrm{~A}$ & $1,67 \mathrm{~A}$ & $1,30 \mathrm{~A}$ & $1,59 \mathrm{~B}$ \\
\hline & $50 \mathrm{DPF}$ & $2,45 \mathrm{~B}$ & $0,71 \mathrm{~B}$ & $0,62 \mathrm{~A}$ & $1,20 \mathrm{~A}$ & $1,20 \mathrm{~A}$ & $1,61 \mathrm{AB}$ \\
\hline & Média & $2,16 \mathrm{~b}$ & $0,76 \mathrm{~b}$ & $0,66 \mathrm{~b}$ & $1,45 \mathrm{~b}$ & $1,35 \mathrm{~b}$ & $1,61 \mathrm{~b}$ \\
\hline Valor de "F" para SI & & $16,53 * *$ & $4,53^{\mathrm{ns}}$ & $1,41^{\mathrm{ns}}$ & $4,10^{\mathrm{ns}}$ & $0,56^{\mathrm{ns}}$ & $1,17^{\mathrm{ns}}$ \\
\hline Valor de "F" para $H$ & & $22,83 * *$ & $9,75 * *$ & $18,34 * *$ & $132,16^{* *}$ & $48,10 * *$ & $1,08^{\mathrm{ns}}$ \\
\hline Valor de "F" para SI x H & & $7,59^{*}$ & $3,62 *$ & $0,85^{\mathrm{ns}}$ & $0,59^{\mathrm{ns}}$ & $5,71 * *$ & $3,07 *$ \\
\hline Valor de "F" para PA & & $1,42^{\mathrm{ns}}$ & $1,80^{\mathrm{ns}}$ & $4,13^{\mathrm{ns}}$ & $0,92^{\text {ns }}$ & $1,61^{\mathrm{ns}}$ & $1,26^{\mathrm{ns}}$ \\
\hline Valor de "F" para SI x PA & & $1,60^{\mathrm{ns}}$ & $0,73^{\text {ns }}$ & $1,78^{\mathrm{ns}}$ & $1,11^{\mathrm{ns}}$ & $0,51^{\mathrm{ns}}$ & $0,35^{\mathrm{ns}}$ \\
\hline Valor de "F" para H x PA & & $0,17^{\mathrm{ns}}$ & $4,83^{*}$ & $1,87^{\mathrm{ns}}$ & $1,22^{\mathrm{ns}}$ & $1,83^{\mathrm{ns}}$ & $0,69^{\text {ns }}$ \\
\hline Valor de "F" para SI x H x PA & & $1,41^{\mathrm{ns}}$ & $1,57^{\mathrm{ns}}$ & $0,87^{\mathrm{ns}}$ & $0,58^{\mathrm{ns}}$ & $0,91^{\mathrm{ns}}$ & $0,58^{\mathrm{ns}}$ \\
\hline $\mathrm{CV}(\%)$ & & 10,4 & 17,2 & 20,6 & 21,0 & 19,0 & 8,9 \\
\hline
\end{tabular}

SI = supressão da irrigação; $\mathrm{H}$ = híbrido; $\mathrm{PA}$ = parcelamento da adubação

${ }^{1}$ Dias antes da floração.

${ }^{2}$ Dias após floração.

Médias seguidas de mesma letra maiúscula dentro de híbridos, e minúsculas entre híbridos, não diferem entre si pelo teste Tukey $(\mathrm{p} \leq 0,05)$.

ns- não significativo; * significativo a $5 \%$ de probabilidade; **significativo a $1 \%$ de probabilidade de erro.

BRS 2121 a supressão nessa época diferiu apenas da testemunha, enquanto que, no BR 205, diferiu das demais épocas. Nos internódios, colmo e pendão, não houve efeito da deficiência hídrica sobre a concentração de $\mathrm{P}$, em ambos os híbridos. De modo geral, esse elemento apresentou maior concentração nos órgãos reprodutivos (pendão, espigas e grãos) do que nos órgãos vegetativos. O híbrido BRS 2121 teve a concentração de P afetada pela época de supressão da irrigação, tanto nas espigas como nos grãos, enquanto que, nesses órgãos, não houve efeito da deficiência hídrica para o BR 205.

De modo geral, os teores de $\mathrm{P}$ nas folhas dos dois híbridos estudados apresentaram-se inferiores àqueles considerados adequados: 0,3 a 0,5\% para plantas cultivadas (Marschner, 1995) e 0,25 a 0,35 para milho em fase de 
TABELA 2. Concentração de fósforo em folhas, internódios basais às espigas, colmo, pendão, espigas e grãos de dois híbridos de milho submetidos a quatro épocas de supressão da irrigação.

\begin{tabular}{|c|c|c|c|c|c|c|c|}
\hline Híbrido & Época de SI & Folhas & Internódios & Colmo & Pendão & Espigas & Grãos \\
\hline & & & & $\%$ & & & \\
\hline \multirow[t]{5}{*}{ BRS 2121} & $10 \mathrm{DAF}$ & $0,13 \mathrm{~A}$ & $0,06 \mathrm{~A}$ & $0,04 \mathrm{~A}$ & $0,25 \mathrm{~A}$ & $0,18 \mathrm{~A}$ & $0,24 \mathrm{~A}$ \\
\hline & $15 \mathrm{DPF}$ & $0,15 \mathrm{AB}$ & $0,87 \mathrm{~A}$ & $0,04 \mathrm{~A}$ & $0,26 \mathrm{~A}$ & $0,18 \mathrm{~A}$ & $0,37 \mathrm{~B}$ \\
\hline & $30 \mathrm{DPF}$ & $0,16 \mathrm{AB}$ & $0,81 \mathrm{~A}$ & $0,04 \mathrm{~A}$ & $0,27 \mathrm{~A}$ & $0,22 \mathrm{AB}$ & $0,45 \mathrm{~B}$ \\
\hline & $50 \mathrm{DPF}$ & $0,17 \mathrm{~B}$ & $0,91 \mathrm{~A}$ & $0,05 \mathrm{~A}$ & $0,26 \mathrm{~A}$ & $0,23 \mathrm{~B}$ & $0,34 \mathrm{AB}$ \\
\hline & Média & $0,15 \mathrm{a}$ & $0,86 \mathrm{a}$ & $0,04 \mathrm{a}$ & $0,26 \mathrm{a}$ & $0,20 \mathrm{a}$ & $0,35 \mathrm{a}$ \\
\hline \multirow[t]{5}{*}{ BR 205} & $10 \mathrm{DAF}$ & $0,07 \mathrm{~A}$ & $0,05 \mathrm{~A}$ & $0,03 \mathrm{~A}$ & $0,11 \mathrm{~A}$ & $0,14 \mathrm{~A}$ & $0,29 \mathrm{~A}$ \\
\hline & $15 \mathrm{DPF}$ & $0,16 \mathrm{~B}$ & $0,05 \mathrm{~A}$ & $0,04 \mathrm{~A}$ & $0,14 \mathrm{~A}$ & $0,16 \mathrm{~A}$ & $0,33 \mathrm{~A}$ \\
\hline & $30 \mathrm{DPF}$ & $0,14 \mathrm{~B}$ & $0,05 \mathrm{~A}$ & $0,04 \mathrm{~A}$ & $0,15 \mathrm{~A}$ & $0,15 \mathrm{~A}$ & $0,35 \mathrm{~A}$ \\
\hline & $50 \mathrm{DPF}$ & $0,16 \mathrm{~B}$ & $0,04 \mathrm{~A}$ & $0,04 \mathrm{~A}$ & $0,13 \mathrm{~A}$ & $0,14 \mathrm{~A}$ & $0,34 \mathrm{~A}$ \\
\hline & Média & $0,13 \mathrm{~b}$ & $0,05 \mathrm{a}$ & $0,04 \mathrm{a}$ & $0,13 \mathrm{~b}$ & $0,15 \mathrm{~b}$ & $0,33 \mathrm{a}$ \\
\hline Valor de "F" para SI & & $7,41 *$ & $0,86^{\mathrm{ns}}$ & $1,84^{\mathrm{ns}}$ & $1,16^{\mathrm{ns}}$ & $0,89^{\text {ns }}$ & $15,73 * *$ \\
\hline Valor de "F" para H & & $8,11 * *$ & $3,02^{\mathrm{ns}}$ & $3,13^{\mathrm{ns}}$ & & $46,65 * *$ & $1,02^{\mathrm{ns}}$ \\
\hline Valor de "F" para SI x H & & $5,17 * *$ & $1,40^{\mathrm{ns}}$ & $0,27^{\mathrm{ns}}$ & $0,26^{\mathrm{ns}}$ & $2,80^{\mathrm{ns}}$ & $2,08^{\mathrm{ns}}$ \\
\hline Valor de "F" para PA & & $0,93^{\mathrm{ns}}$ & $0,39^{\text {ns }}$ & $1,85^{\mathrm{ns}}$ & $0,47^{\mathrm{ns}}$ & $0,67^{\mathrm{ns}}$ & $0,10^{\mathrm{ns}}$ \\
\hline Valor de "F" para SI x PA & & $1,88^{\mathrm{ns}}$ & $0,82^{\mathrm{ns}}$ & $2,09^{\mathrm{ns}}$ & $1,97^{\mathrm{ns}}$ & $1,56^{\mathrm{ns}}$ & $1,02^{\mathrm{ns}}$ \\
\hline Valor de "F" para H x PA & & $0,87^{\mathrm{ns}}$ & $1,67^{\mathrm{ns}}$ & $2,35^{\mathrm{ns}}$ & $1,87^{\mathrm{ns}}$ & $1,14^{\mathrm{ns}}$ & $0,02^{\mathrm{ns}}$ \\
\hline Valor de "F" para SI x H x PA & & $1,41^{\mathrm{ns}}$ & $1,36^{\mathrm{ns}}$ & $0,36^{\mathrm{ns}}$ & $0,48^{\mathrm{ns}}$ & $0,67^{\mathrm{ns}}$ & $0,56^{\mathrm{ns}}$ \\
\hline $\mathrm{CV}(\%)$ & & 17,9 & 27,0 & 27,4 & 22,0 & 20,01 & 26,9 \\
\hline
\end{tabular}

Médias seguidas de mesma letra maiúscula, dentro de híbridos, e minúscula, entre híbridos, não diferem entre si pelo teste Tukey $(\mathrm{p} \leq 0,05)$.

ns- não significativo; * significativo a $5 \%$ de probabilidade; **significativo a $1 \%$ de probabilidade de erro.

embonecamento, segundo Barber \& Olson (1968). Novamente a época de avaliação pode explicar os valores observados. Os teores desse nutriente foram ainda mais baixos quando houve maior limitação hídrica (Tabela 2). Premachandra et al. (1989) também observaram redução nos teores de $\mathrm{P}$ na folha, em plantas de milho sob deficiência hídrica, na fase vegetativa, em condições de campo.

A supressão da irrigação aos 15 DPF proporcionou a menor concentração foliar de K
(Tabela 3), no híbrido BRS 2121. No BR 205, não houve diferença significativa entre as épocas de supressão da irrigação para essa variável. Nos internódios, colmo e pendão do BRS 2121, não houve efeito da supressão da irrigação sobre a concentração desse nutriente. Nas espigas e grãos do mesmo híbrido, houve redução da concentração de K com a supressão da irrigação aos 10 DAF. Inversamente, o híbrido BR 205 apresentou redução nos teores desse cátion nos internódios, com a SI, aos 10 DAF. Nos demais 
TABELA 3. Concentração de potássio em folhas, internódios basais às espigas, colmo, pendão, espigas e grãos de dois híbridos de milho submetidos a quatro épocas de supressão da irrigação.

\begin{tabular}{|c|c|c|c|c|c|c|c|}
\hline Híbrido & Época de SI & Folhas & Internódios & Colmo & Pendão & Espigas & Grãos \\
\hline & & \multicolumn{6}{|c|}{$\%$} \\
\hline \multirow[t]{5}{*}{ BRS 2121} & $10 \mathrm{DAF}$ & $2,11 \mathrm{AB}$ & $0,97 \mathrm{~A}$ & $0,99 \mathrm{~A}$ & $1,24 \mathrm{~A}$ & $1,31 \mathrm{~A}$ & $0,50 \mathrm{~A}$ \\
\hline & $15 \mathrm{DPF}$ & $1,85 \mathrm{~B}$ & $1,12 \mathrm{~A}$ & $1,05 \mathrm{~A}$ & $1,21 \mathrm{~A}$ & $1,39 \mathrm{AB}$ & $0,60 \mathrm{AB}$ \\
\hline & $30 \mathrm{DPF}$ & $2,19 \mathrm{~A}$ & $1,16 \mathrm{~A}$ & $1,18 \mathrm{~A}$ & $1,32 \mathrm{~A}$ & $1,73 \mathrm{AB}$ & $0,65 \mathrm{~B}$ \\
\hline & $50 \mathrm{DPF}$ & $2,18 \mathrm{~A}$ & $1,17 \mathrm{~A}$ & $1,18 \mathrm{~A}$ & $1,19 \mathrm{~A}$ & $1,69 \mathrm{~B}$ & $0,53 \mathrm{AB}$ \\
\hline & Média & $2,08 \mathrm{a}$ & $1,11 \mathrm{a}$ & $1,10 \mathrm{a}$ & $1,26 \mathrm{a}$ & $1,53 \mathrm{a}$ & $0,57 \mathrm{a}$ \\
\hline \multirow[t]{5}{*}{ BR 205} & $10 \mathrm{DAF}$ & $1,82 \mathrm{~A}$ & $0,76 \mathrm{~A}$ & $0,85 \mathrm{~A}$ & $1,07 \mathrm{~A}$ & $1,09 \mathrm{~A}$ & $0,50 \mathrm{~A}$ \\
\hline & $15 \mathrm{DPF}$ & $1,82 \mathrm{~A}$ & $0,96 \mathrm{AB}$ & $1,06 \mathrm{~A}$ & $1,16 \mathrm{~A}$ & $1,23 \mathrm{~A}$ & $0,54 \mathrm{~A}$ \\
\hline & $30 \mathrm{DPF}$ & $1,91 \mathrm{~A}$ & $1,05 \mathrm{~B}$ & $1,11 \mathrm{~A}$ & $1,23 \mathrm{~A}$ & $1,24 \mathrm{~A}$ & $0,54 \mathrm{~A}$ \\
\hline & $50 \mathrm{DPF}$ & $1,74 \mathrm{~A}$ & $0,91 \mathrm{AB}$ & $0,88 \mathrm{~A}$ & $1,07 \mathrm{~A}$ & $1,12 \mathrm{~A}$ & $0,52 \mathrm{~A}$ \\
\hline & Média & $1,83 \mathrm{~b}$ & $0,92 \mathrm{a}$ & $0,98 \mathrm{a}$ & $1,13 \mathrm{~b}$ & $1,18 \mathrm{~b}$ & $0,53 \mathrm{a}$ \\
\hline Valor de "F" para SI & & $1,43^{\text {ns }}$ & $7,18 *$ & $1,58^{\mathrm{ns}}$ & $1,75^{\mathrm{ns}}$ & $2,16^{\mathrm{ns}}$ & $31,27 * *$ \\
\hline Valor de "F" para H & & $21,83^{* *}$ & $13,83^{* *}$ & $2,84^{\mathrm{ns}}$ & $9,18 * *$ & $30,01 * *$ & $5,86^{*}$ \\
\hline Valor de "F" para SI x H & & $2,26^{\mathrm{ns}}$ & $0,46^{\mathrm{ns}}$ & $0,78^{\mathrm{ns}}$ & $0,91^{\mathrm{ns}}$ & $2,64^{\mathrm{ns}}$ & $0,73^{\mathrm{ns}}$ \\
\hline Valor de "F" para PA & & $2,18^{\mathrm{ns}}$ & $1,31^{\mathrm{ns}}$ & $2,55^{\mathrm{ns}}$ & $0,08^{\text {ns }}$ & $1,08^{\mathrm{ns}}$ & $0,11^{\mathrm{ns}}$ \\
\hline Valor de "F" para SI x PA & & $0,52^{\mathrm{ns}}$ & $1,08^{\mathrm{ns}}$ & $0,83^{\mathrm{ns}}$ & $0,91^{\mathrm{ns}}$ & $0,82^{\mathrm{ns}}$ & $0,96^{\mathrm{ns}}$ \\
\hline Valor de "F" para H x PA & & $0,82^{\text {ns }}$ & $1,11^{\mathrm{ns}}$ & $0,85^{\text {ns }}$ & $0,58^{\mathrm{ns}}$ & $1,98^{\mathrm{ns}}$ & $0,22^{\text {ns }}$ \\
\hline $\begin{array}{l}\text { Valor de "F" para SI x H x } \\
\text { PA }\end{array}$ & & $0,93^{\mathrm{ns}}$ & $1,11^{\mathrm{ns}}$ & $1,34^{\mathrm{ns}}$ & $1,21^{\mathrm{ns}}$ & $1,24^{\mathrm{ns}}$ & $0,56^{\mathrm{ns}}$ \\
\hline $\mathrm{CV}(\%)$ & & 12,1 & 20,9 & 30,7 & 15,2 & 20,01 & 19,4 \\
\hline
\end{tabular}

Médias seguidas de mesma letra maiúscula, dentro dos híbridos, e minúsculas entre híbridos não diferem entre si pelo teste Tukey $(\mathrm{p} \leq 0,05)$.

ns- não significativo; * significativo a $5 \%$ de probabilidade; **significativo a $1 \%$ de probabilidade de erro.

órgãos desse híbrido, não houve efeito da condição hídrica sobre a concentração de K.

A pouca influência dos regimes hídricos sobre a concentração de $\mathrm{K}$ nos diferentes órgãos pode ser devido ao fato de que grande parte da absorção desse nutriente em plantas de milho ocorre até o pendoamento (Flannery, 1987), época em que praticamente não houve limitação hídrica para as plantas.

A concentração de $\mathrm{Ca}$ (Tabela 4) não foi afetada pela supressão da irrigação no híbrido BRS 2121, em quaisquer dos órgãos estudados, nem nos internódios, colmo e grãos, no BR 205. Entretanto, neste último, houve redução em folhas e no pendão e aumento em espigas, com a supressão da irrigação aos 10 DAF.

Os teores de Ca nos órgãos vegetativos se mantiveram dentro do limite adequado para plantas de milho (Islam et al., 1987). De modo geral, o híbrido BR 205 apresentou teores superiores desse nutriente, com exceção dos grãos. 
TABELA 4. Concentração de cálcio em folhas, internódios basais às espigas, colmo, pendão, espigas e grãos de dois híbridos de milho submetidos a quatro épocas de supressão da irrigação.

\begin{tabular}{|c|c|c|c|c|c|c|c|}
\hline Híbrido & Época de SI & Folhas & Internódios & Colmo & Pendão & Espigas & Grãos \\
\hline & & & & $\%$ & & & \\
\hline \multirow[t]{5}{*}{ BRS 2121} & $10 \mathrm{DAF}$ & $0,66 \mathrm{AB}$ & $0,22 \mathrm{~A}$ & $0,25 \mathrm{~A}$ & $0,17 \mathrm{~A}$ & $0,11 \mathrm{~A}$ & $0,01 \mathrm{~A}$ \\
\hline & $15 \mathrm{DPF}$ & 0,63 & $0,19 \mathrm{~A}$ & $0,20 \mathrm{~A}$ & $0,18 \mathrm{~A}$ & $0,10 \mathrm{~A}$ & $0,01 \mathrm{~A}$ \\
\hline & $30 \mathrm{DPF}$ & $0,70 \mathrm{~A}$ & $0,22 \mathrm{~A}$ & $0,24 \mathrm{~A}$ & $0,20 \mathrm{~A}$ & $0,12 \mathrm{~A}$ & $0,01 \mathrm{~A}$ \\
\hline & $50 \mathrm{DPF}$ & $0,72 \mathrm{~A}$ & $0,22 \mathrm{~A}$ & $0,23 \mathrm{~A}$ & $0,23 \mathrm{~A}$ & $0,12 \mathrm{~B}$ & $0,01 \mathrm{~A}$ \\
\hline & Média & $0,68 \mathrm{a}$ & $0,21 \mathrm{a}$ & $0,23 \mathrm{a}$ & $0,20 \mathrm{a}$ & $0,11 \mathrm{a}$ & $0,01 \mathrm{a}$ \\
\hline \multirow[t]{5}{*}{ BR 205} & $10 \mathrm{DAF}$ & $0,73 \mathrm{~A}$ & $0,24 \mathrm{~A}$ & $0,28 \mathrm{~A}$ & $0,20 \mathrm{~A}$ & $0,16 \mathrm{~A}$ & $0,009 \mathrm{~A}$ \\
\hline & $15 \mathrm{DPF}$ & $0,88 \mathrm{AB}$ & $0,20 \mathrm{~A}$ & $0,23 \mathrm{~A}$ & $0,33 \mathrm{AB}$ & $0,11 \mathrm{~B}$ & $0,010 \mathrm{~A}$ \\
\hline & $30 \mathrm{DPF}$ & $0,92 \mathrm{~B}$ & $0,24 \mathrm{~A}$ & $0,26 \mathrm{~A}$ & $0,35 \mathrm{~B}$ & $0,11 \mathrm{~B}$ & $0,008 \mathrm{~A}$ \\
\hline & $50 \mathrm{DPF}$ & $0,98 \mathrm{~B}$ & $0,22 \mathrm{~A}$ & $0,25 \mathrm{~A}$ & $0,43 \mathrm{~A}$ & $0,11 \mathrm{~B}$ & $0,008 \mathrm{~A}$ \\
\hline & Média & $0,88 \mathrm{~b}$ & $0,23 \mathrm{a}$ & $0,26 \mathrm{~b}$ & $0,33 \mathrm{~b}$ & $0,12 \mathrm{~b}$ & $0,009 \mathrm{~b}$ \\
\hline Valor de "F" para SI & & $8,81 *$ & $3,48^{*}$ & $6,03 *$ & $25,12 * *$ & $2,64^{\mathrm{ns}}$ & $2,20^{\mathrm{ns}}$ \\
\hline Valor de "F" para H & & $27,11 * *$ & $1,87 * *$ & $4,69 *$ & $29,08 * *$ & $0,67^{\mathrm{ns}}$ & $5,95^{*}$ \\
\hline Valor de "F" para SI x H & & $1,46^{\mathrm{ns}}$ & $0,18^{\mathrm{ns}}$ & $0,11^{\mathrm{ns}}$ & $2,14^{\mathrm{ns}}$ & $3,99 *$ & $0,87^{\mathrm{ns}}$ \\
\hline Valor de "F" para PA & & $1,38^{\mathrm{ns}}$ & $0,11^{\mathrm{ns}}$ & $0,18^{\text {ns }}$ & $1,20^{\mathrm{ns}}$ & $0,11^{\mathrm{ns}}$ & $0,95^{\text {ns }}$ \\
\hline Valor de "F" para SI x PA & & $0,21^{\mathrm{ns}}$ & $0,44^{\mathrm{ns}}$ & $0,91^{\mathrm{ns}}$ & $0,80^{\mathrm{ns}}$ & $0,86^{\mathrm{ns}}$ & $1,59^{\mathrm{ns}}$ \\
\hline Valor de "F" para H x PA & & $0,69^{\mathrm{ns}}$ & $0,52^{\mathrm{ns}}$ & $1,31^{\mathrm{ns}}$ & $0,17^{\mathrm{ns}}$ & $1,83^{\mathrm{ns}}$ & $0,95^{\mathrm{ns}}$ \\
\hline Valor de "F" para SI x H x PA & & $0,77^{\mathrm{ns}}$ & $0,44^{\mathrm{ns}}$ & $0,38^{\mathrm{ns}}$ & $0,96^{\mathrm{ns}}$ & $1,49^{\mathrm{ns}}$ & $1,59^{\mathrm{ns}}$ \\
\hline $\mathrm{CV}(\%)$ & & 20,5 & 22,3 & 21,1 & 39,7 & 26,5 & 25,9 \\
\hline
\end{tabular}

Médias seguidas de mesma letra maiúscula dentro de híbrido, e minúscula entre híbridos, não diferem entre si pelo teste Tukey $(\mathrm{p} \leq 0,05)$.

ns- não significativo; * significativo a $5 \%$ de probabilidade; **significativo a $1 \%$ de probabilidade de erro.

Premachandra et al. (1989), trabalhando com oito híbridos de milho, em experimento de campo, encontraram respostas diferenciadas destes ao déficit hídrico com relação à concentração de Ca no suco celular de folhas; alguns apresentaram diminuição, entretanto, aumento na concentração foi a resposta mais frequiente. Por outro lado, em outro trabalho, os mesmos autores verificaram que a concentração desse nutriente no tecido seco não diferiu entre plantas de milho submetidas a estresse hídrico ou bem irrigadas (Premachandra et al.,1990).
O magnésio (Mg) (Tabela 5) teve sua concentração reduzida pela supressão da irrigação aos 10 DAF apenas em grãos do híbrido BRS 2121 e em internódios e pendão do BR 205. Quanto aos híbridos, o BR 205 apresentou concentração mais elevada de $\mathrm{Mg}$ em folhas e no pendão, entretanto, em grãos, o BRS 2121 foi o que apresentou a maior concentração desse elemento; para os demais órgãos, a concentração foi semelhante nos dois híbridos.

A redução nos teores de $\mathrm{Mg}$ nos internódios do híbrido BR 205 não se refletiu nos 
TABELA 5. Concentração de magnésio em folhas, internódios basais às espigas, colmo, espigas e grãos de dois híbridos de milho submetidos a quatro épocas de supressão da irrigação.

\begin{tabular}{|c|c|c|c|c|c|c|c|}
\hline Híbrido & Época de SI & Folhas & Internódios & Colmo & Pendão & Espigas & Grãos \\
\hline & & & & $\%$ & & & \\
\hline \multirow[t]{5}{*}{ BRS 2121} & $10 \mathrm{DAF}$ & $0,23 \mathrm{~A}$ & $0,16 \mathrm{~A}$ & $0,18 \mathrm{~A}$ & $0,17 \mathrm{~A}$ & $0,13 \mathrm{~A}$ & $0,12 \mathrm{~A}$ \\
\hline & $15 \mathrm{DPF}$ & 0,24 & $0,17 \mathrm{~A}$ & $0,18 \mathrm{~A}$ & $0,17 \mathrm{~A}$ & $0,14 \mathrm{~A}$ & $0,17 \mathrm{BC}$ \\
\hline & $30 \mathrm{DPF}$ & $0,24 \mathrm{~A}$ & $0,17 \mathrm{~A}$ & $0,18 \mathrm{~A}$ & $0,18 \mathrm{~A}$ & $0,16 \mathrm{~A}$ & $0,20 \mathrm{C}$ \\
\hline & $50 \mathrm{DPF}$ & $0,26 \mathrm{~A}$ & $0,17 \mathrm{~A}$ & $0,19 \mathrm{~A}$ & $0,19 \mathrm{~A}$ & $0,16 \mathrm{~B}$ & $0,16 \mathrm{AB}$ \\
\hline & Média & $0,24 \mathrm{a}$ & $0,17 \mathrm{a}$ & $0,18 \mathrm{a}$ & $0,18 \mathrm{a}$ & $0,15 \mathrm{a}$ & $0,16 \mathrm{a}$ \\
\hline \multirow[t]{5}{*}{ BR 205} & $10 \mathrm{DAF}$ & $0,27 \mathrm{~A}$ & $0,15 \mathrm{~A}$ & $0,18 \mathrm{~A}$ & $0,17 \mathrm{~A}$ & $0,14 \mathrm{~A}$ & $0,12 \mathrm{~A}$ \\
\hline & $15 \mathrm{DPF}$ & $0,32 \mathrm{~A}$ & $0,17 \mathrm{~B}$ & $0,20 \mathrm{~A}$ & $0,28 \mathrm{~B}$ & $0,14 \mathrm{~A}$ & $0,14 \mathrm{~A}$ \\
\hline & $30 \mathrm{DPF}$ & $0,31 \mathrm{~B}$ & $0,17 \mathrm{~B}$ & $0,20 \mathrm{~A}$ & $0,25 \mathrm{~B}$ & $0,14 \mathrm{~A}$ & $0,16 \mathrm{~A}$ \\
\hline & $50 \mathrm{DPF}$ & $0,31 \mathrm{~B}$ & $0,17 \mathrm{~A}$ & $0,19 \mathrm{~A}$ & $0,27 \mathrm{~A}$ & $0,13 \mathrm{~A}$ & $0,15 \mathrm{~A}$ \\
\hline & Média & $0,30 \mathrm{~b}$ & 0,16 a & $0,19 \mathrm{a}$ & $0,24 \mathrm{~b}$ & $0,14 \mathrm{~b}$ & $0,14 \mathrm{a}$ \\
\hline Valor de "F" para SI & & $1,31^{\mathrm{ns}}$ & $1,55^{\mathrm{ns}}$ & $0,56^{\mathrm{ns}}$ & $11,51 * *$ & $1,03^{\mathrm{ns}}$ & $2,20^{\mathrm{ns}}$ \\
\hline Valor de "F" para H & & $16,18 * *$ & $0,10^{\mathrm{ns}}$ & $0,58^{\mathrm{ns}}$ & $87,05 * *$ & $1,01^{\mathrm{ns}}$ & $5,95^{*}$ \\
\hline Valor de "F" para SI x H & & $0,37^{\mathrm{ns}}$ & $0,30^{\mathrm{ns}}$ & $0,21^{\mathrm{ns}}$ & $10,21 * *$ & $1,63^{\mathrm{ns}}$ & $0,87^{\mathrm{ns}}$ \\
\hline Valor de "F" para PA & & $0,01^{\mathrm{ns}}$ & $0,86^{\mathrm{ns}}$ & $0,76^{\mathrm{ns}}$ & $0,39^{\text {ns }}$ & $0,99^{\text {ns }}$ & $0,95^{\mathrm{ns}}$ \\
\hline Valor de "F" para SI x PA & & $0,92^{\text {ns }}$ & $0,75^{\mathrm{ns}}$ & $0,75^{\mathrm{ns}}$ & $1,16^{\mathrm{ns}}$ & $1,65^{\mathrm{ns}}$ & $1,59^{\mathrm{ns}}$ \\
\hline Valor de "F" para H x PA & & $0,63^{\text {ns }}$ & $0,62^{\text {ns }}$ & $1,26^{\mathrm{ns}}$ & $0,65^{\text {ns }}$ & $1,83^{\text {ns }}$ & $0,95^{\text {ns }}$ \\
\hline Valor de "F" para SI x H x PA & & $1,43^{\mathrm{ns}}$ & $0,94^{\mathrm{ns}}$ & $0,77^{\mathrm{ns}}$ & $1,41^{\mathrm{ns}}$ & $1,33^{\mathrm{ns}}$ & $1,59^{\mathrm{ns}}$ \\
\hline $\mathrm{CV}(\%)$ & & 23,1 & 22,3 & 25,5 & 13,8 & 17,6 & 24,0 \\
\hline
\end{tabular}

Médias seguidas de mesma letra maiúscula dentro de híbridos, e minúscula entre híbridos não diferem entre si pelo teste Tukey $(\mathrm{p} \leq 0,05)$.

ns- não significativo; * significativo a $5 \%$ de probabilidade; ** significativo a $1 \%$ de probabilidade de erro.

grãos, levando à suposição de que a translocação desse elemento não foi afetada nesse híbrido, o inverso aconteceu no BRS 2121, em que a concentração foi afetada pela deficiência hídrica apenas nos grãos. A redução não só desse elemento, como também de outros, nos grãos, no híbrido BRS 2121, permite inferir que a translocação de nutrientes foi mais afetada pela deficiência hídrica nesse híbrido do que no BR 205.

De modo geral, os teores de Mg encontrados neste experimento estão dentro do limite satisfatório para o crescimento de plantas (Marschner, 1995) e particularmente do milho (Barber e Olson, 1968), embora, nos grãos do híbrido BR 205, tenham sido inferiores aos encontrados por Hiroce et al. (1989).

Em outros trabalhos realizados com milho, sob deficiência hídrica, observouse aumento na concentração de $\mathrm{Mg}$ no suco celular de folhas, tanto de plantas cultivadas em condições de campo (Premachandra et al., 1989; 1990) como em casa-de-vegetação (Premachandra et al., 1992). 
A supressão da irrigação aos 10 DAF reduziu a concentração de $\mathrm{S}$ (Tabela 6) das espigas do híbrido BRS 2121 e das folhas e colmos do híbrido BR 205. Nos demais órgãos, a deficiência hídrica não alterou a concentração do nutriente. Nos grãos, o BRS 2121 apresentou concentração de $\mathrm{S}$ superior, o que evidencia a sua qualidade protéica melhorada, com maior proporção de metionina.

A concentração de $\mathrm{S}$, nos diferentes órgãos, foi mais afetada pelo híbrido do que pela condição hídrica. Nos grãos, os valores foram muito baixos, comparando-se aos encontrados por Hiroce et al. (1989).

Experimento conduzido em casa de vegetação

Os teores de $\mathrm{N}$ (Tabela 7) nas folhas e colmo foram superiores nos tratamentos onde ocorreu deficiência hídrica, para ambos os híbridos. Nas raízes, o teor de $\mathrm{N}$ diferiu entre os tratamentos T1 e T7, sendo superior no último

TABELA 6. Concentração de enxofre em folhas, internódios basais às espigas, colmo, pendão, espigas e grãos de dois híbridos de milho submetidos a quatro épocas de supressão da irrigação.

\begin{tabular}{|c|c|c|c|c|c|c|c|}
\hline Híbrido & Época de SI & Folhas & Internódios & Colmo & Pendão & Espigas & Grãos \\
\hline & & & & $\%$ & & & \\
\hline \multirow[t]{5}{*}{ BRS 2121} & $10 \mathrm{DAF}$ & $0,13 \mathrm{~A}$ & $0,05 \mathrm{~A}$ & $0,05 \mathrm{~A}$ & $0,14 \mathrm{~A}$ & $0,09 \mathrm{~A}$ & $0,09 \mathrm{~A}$ \\
\hline & $15 \mathrm{DPF}$ & $0,16 \mathrm{~A}$ & $0,06 \mathrm{~A}$ & $0,06 \mathrm{~A}$ & $0,15 \mathrm{~A}$ & $0,11 \mathrm{~B}$ & $0,09 \mathrm{~A}$ \\
\hline & $30 \mathrm{DPF}$ & $0,14 \mathrm{~A}$ & $0,06 \mathrm{~A}$ & $0,06 \mathrm{~A}$ & $0,14 \mathrm{~A}$ & $0,11 \mathrm{~B}$ & $0,09 \mathrm{~A}$ \\
\hline & $50 \mathrm{DPF}$ & $0,13 \mathrm{~A}$ & $0,06 \mathrm{~A}$ & $0,06 \mathrm{~A}$ & $0,14 \mathrm{~A}$ & $0,10 \mathrm{AB}$ & $0,09 \mathrm{~A}$ \\
\hline & Média & $0,14 \mathrm{a}$ & $0,06 \mathrm{a}$ & 0,06 a & $0,14 \mathrm{a}$ & $0,10 \mathrm{a}$ & $0,09 \mathrm{a}$ \\
\hline \multirow[t]{5}{*}{ BR 205} & $10 \mathrm{DAF}$ & $0,16 \mathrm{~A}$ & $0,09 \mathrm{~A}$ & $0,08 \mathrm{~A}$ & $0,14 \mathrm{~A}$ & $0,12 \mathrm{~A}$ & $0,08 \mathrm{~A}$ \\
\hline & $15 \mathrm{DPF}$ & $0,18 \mathrm{AB}$ & $0,08 \mathrm{~B}$ & $0,09 \mathrm{AB}$ & $0,15 \mathrm{~A}$ & $0,12 \mathrm{~A}$ & $0,07 \mathrm{~A}$ \\
\hline & $30 \mathrm{DPF}$ & $0,18 \mathrm{AB}$ & $0,09 \mathrm{~A}$ & $0,08 \mathrm{AB}$ & $0,15 \mathrm{~A}$ & $0,12 \mathrm{~A}$ & $0,07 \mathrm{~A}$ \\
\hline & $50 \mathrm{DPF}$ & $0,21 \mathrm{~B}$ & $0,09 \mathrm{~A}$ & $0,09 \mathrm{~B}$ & 0,16 & $0,12 \mathrm{~A}$ & $0,08 \mathrm{~A}$ \\
\hline & Média & $0,18 \mathrm{~b}$ & $0,09 \mathrm{~b}$ & $0,08 \mathrm{~b}$ & $0,15 \mathrm{a}$ & $0,12 \mathrm{~b}$ & $0,08 \mathrm{~b}$ \\
\hline Valor de "F" para SI & & $3,47^{\mathrm{ns}}$ & $0,41^{\mathrm{ns}}$ & $3,45^{\text {ns }}$ & $0,90^{\text {ns }}$ & $3,16^{\mathrm{ns}}$ & $1,06^{\mathrm{ns}}$ \\
\hline Valor de "F" para H & & $62,79 * *$ & $150,60 * *$ & $177,55^{* *}$ & $3,83^{\text {ns }}$ & $34,92 * *$ & $31,56 * *$ \\
\hline Valor de "F" para SI x H & & $6,09 * *$ & $1,49^{\text {ns }}$ & $0,69^{\text {ns }}$ & $2,16^{\mathrm{ns}}$ & $1,14^{\mathrm{ns}}$ & $1,05^{\mathrm{ns}}$ \\
\hline Valor de "F" para PA & & $1,12^{\mathrm{ns}}$ & $2,07^{\mathrm{ns}}$ & $1,32^{\mathrm{ns}}$ & $0,73^{\text {ns }}$ & $0,57^{\text {ns }}$ & $0,51^{\mathrm{ns}}$ \\
\hline Valor de "F" para SI x PA & & $1,02^{\mathrm{ns}}$ & $0,46^{\mathrm{ns}}$ & $1,88^{\mathrm{ns}}$ & $1,03^{\mathrm{ns}}$ & $0,73^{\mathrm{ns}}$ & $0,85^{\mathrm{ns}}$ \\
\hline Valor de "F" para H x PA & & $1,81^{\mathrm{ns}}$ & $0,68^{\mathrm{ns}}$ & $0,05^{\text {ns }}$ & $0,42^{\text {ns }}$ & $0,92^{\mathrm{ns}}$ & $2,11^{\mathrm{ns}}$ \\
\hline Valor de "F" para SI x H x PA & & $1,58^{\mathrm{ns}}$ & $1,92^{\mathrm{ns}}$ & $1,96^{\mathrm{ns}}$ & $0,80^{\text {ns }}$ & $0,49^{\text {ns }}$ & $0,29^{\text {ns }}$ \\
\hline $\mathrm{CV}(\%)$ & & 14,1 & 12,4 & 12,4 & 13,2 & 11,5 & 11,9 \\
\hline
\end{tabular}

Médias seguidas de mesma letra maiúscula, dentro dos híbridos, e minúscula entre híbridos, não diferem entre si pelo teste Tukey $(\mathrm{p} \leq 0,05)$.

ns- não significativo; * significativo a $5 \%$ de probabilidade; **significativo a $1 \%$ de probabilidade de erro. 
híbrido, o BRS 2121. No BR 205, os teores de $\mathrm{N}$ radicular nos tratamentos $\mathrm{T} 1$ e $\mathrm{T} 3$ não diferiram entre si e foram significativamente inferiores aos dos tratamentos T5 e T7.

Diferente do que ocorreu em campo, os teores de $\mathrm{N}$ foram mais elevados em BR 205 do que em BRS 2121, em folhas e no colmo. $\mathrm{O}$ maior acúmulo de $\mathrm{N}$ em folhas, colmo e raízes quando houve maior intervalo entre as irrigações pode ter ocorrido devido a uma maior redução no acúmulo de matéria seca do que na absorção desse nutriente, promovida pelo estresse hídrico.
Segundo Chapin (1991), pode-se esperar aumento na concentração de alguns nutrientes nos tecidos vegetais se o suprimento de água restringe mais fortemente o crescimento que a absorção dos mesmos, o que explicaria o comportamento observado no presente trabalho. Aumentos na concentração de $\mathrm{N}$ na folha, sob condições de deficiência hídrica, foram também encontrados em trigo, por Heitholt et al. (1991), e em milho, por Premachandra et al. (1990).

Os teores de fósforo (P) (Tabela 7) das folhas, em ambos os híbridos, apresentou comportamento semelhante aos teores de $\mathrm{N}$.

TABELA 7. Concentração de nitrogênio e fósforo em folhas, colmo e raiz de dois híbridos de milho submetidos a diferentes intervalos da irrigação .

\begin{tabular}{|c|c|c|c|c|c|c|c|}
\hline \multirow[b]{2}{*}{ Híbrido } & \multirow[b]{2}{*}{$\begin{array}{l}\text { Intervalo } \\
\text { irrigação } \\
\text { (dias) }\end{array}$} & \multicolumn{3}{|c|}{$\mathrm{N}$} & \multicolumn{3}{|c|}{$\mathrm{P}$} \\
\hline & & Folhas & Colmo & Raiz & Folhas & Colmo & Raiz \\
\hline & & & & & $\%$ & & \\
\hline \multirow[t]{5}{*}{ BRS 2121} & 1 & $1,16 \mathrm{~A}$ & $0,44 \mathrm{~A}$ & $0,69 \mathrm{~A}$ & $0,06 \mathrm{~A}$ & $0,04 \mathrm{~A}$ & $0,11 \mathrm{~A}$ \\
\hline & 3 & $1,46 \mathrm{~B}$ & $1,11 \mathrm{~B}$ & $0,83 \mathrm{AB}$ & $0,08 \mathrm{~B}$ & $0,06 \mathrm{AB}$ & $0,13 \mathrm{BC}$ \\
\hline & 5 & $1,44 \mathrm{~B}$ & $0,81 \mathrm{C}$ & $0,86 \mathrm{AB}$ & $0,09 \mathrm{~B}$ & $0,06 \mathrm{AB}$ & $0,13 \mathrm{C}$ \\
\hline & 7 & $1,49 \mathrm{~B}$ & $1,16 \mathrm{~B}$ & $0,89 \mathrm{~B}$ & $0,08 \mathrm{~B}$ & $0,09 \mathrm{~B}$ & $0,11 \mathrm{AB}$ \\
\hline & Média & $1,39 \mathrm{a}$ & $0,88 \mathrm{a}$ & $0,82 \mathrm{a}$ & $0,08 \mathrm{a}$ & 0,06 a & $0,12 \mathrm{a}$ \\
\hline \multirow[t]{5}{*}{ BR 205} & 1 & $1,29 \mathrm{~A}$ & $0,56 \mathrm{~A}$ & $0,63 \mathrm{~A}$ & $0,08 \mathrm{~A}$ & $0,06 \mathrm{~A}$ & $0,11 \mathrm{~A}$ \\
\hline & 3 & $1,43 \mathrm{AB}$ & $0,74 \mathrm{~B}$ & $0,72 \mathrm{AB}$ & $0,08 \mathrm{~A}$ & $0,06 \mathrm{~A}$ & $0,12 \mathrm{AB}$ \\
\hline & 5 & $1,79 \mathrm{~B}$ & $1,37 \mathrm{~B}$ & $1,02 \mathrm{~B}$ & $0,12 \mathrm{~B}$ & $0,10 \mathrm{~B}$ & $0,13 \mathrm{AB}$ \\
\hline & 7 & $1,79 \mathrm{~B}$ & $1,78 \mathrm{C}$ & $1,13 \mathrm{~B}$ & $0,10 \mathrm{~B}$ & $0,15 \mathrm{C}$ & $0,13 \mathrm{~B}$ \\
\hline & Média & $1,58 \mathrm{~b}$ & $1,12 \mathrm{~b}$ & $0,87 \mathrm{a}$ & $0,09 \mathrm{~b}$ & $0,09 \mathrm{~b}$ & $0,12 \mathrm{a}$ \\
\hline Valor de "F" para $H$ & & $18,55 * *$ & $20,62 * *$ & $1,11^{\mathrm{ns}}$ & $13,59 * *$ & $12,54 * *$ & $0,18^{\mathrm{ns}}$ \\
\hline Valor de "F" para I & & $19,32 * *$ & $61,31 * *$ & $10,11^{\text {ns }}$ & $17,36^{\mathrm{ns}}$ & $13,13 * *$ & $3,00^{*}$ \\
\hline Valor de "F" para H x I & & $3,77 *$ & $19,71 * *$ & $2,74^{\mathrm{ns}}$ & $1,88^{\mathrm{ns}}$ & $2,63^{\mathrm{ns}}$ & $2,01^{\mathrm{ns}}$ \\
\hline $\mathrm{CV}(\%)$ & & 8,3 & 14,5 & 16,9 & 17,7 & 29,2 & 10,3 \\
\hline
\end{tabular}

Médias seguidas de mesma letra maiúscula dentro de híbridos, e minúsculas entre híbridos não diferem entre si pelo teste Tukey $(\mathrm{p} \leq 0,05)$.

ns- não significativo; * significativo a $5 \%$ de probabilidade; **significativo a $1 \%$ de probabilidade de erro. 
No colmo do híbrido BRS 2121, o teor de P aumentou à medida que os intervalos entre as irrigações aumentaram, com diferença significativa apenas entre os tratamentos T1 e T7. No BR 205, os intervalos de um e três dias entre irrigação proporcionaram as menores concentrações do nutriente, o intervalo de cinco dias apresentaram valores intermediários e de sete dias as concentrações mais elevadas. O teor de $\mathrm{P}$ nas raízes no híbrido, BRS 2121, aumentou com o aumento no intervalo entre as irrigações até o intervalo de cinco dias, quando esse intervalo foi de sete dias o teor de $\mathrm{P}$ diminuiu, assemelhando-se ao encontrado para a testemunha; para o híbrido BR 205, o P aumentou progressivamente com o aumento no intervalo entre as irrigações. Comparando-se os híbridos, o BR 205 apresentou concentrações mais elevadas de $\mathrm{P}$ em folhas e no colmo (no campo, as concentrações foram iguais) e semelhante ao BRS 2121 em raízes.

Em experimento de casa-de-vegetação, Premachandra et al. (1992) observaram respostas diferenciadas entre híbridos de milho quanto ao efeito do deficit hídrico sobre o teor de $\mathrm{P}$ na folha. No presente trabalho, as concentrações de $\mathrm{P}$ encontradas indicam efeito de aumento na concentração do nutriente provocado por redução na fitomassa, em função do déficit hídrico.

A concentração foliar de $\mathrm{K}$ (Tabela 8) foi inferior na testemunha, no BRS 2121, e no BR 205 também no intervalo de três dias entre irrigações, em relação aos demais tratamentos. No colmo e nas raízes, os teores de K, em ambos os híbridos, aumentaram com o aumento no intervalo entre irrigações. Em todos os órgãos estudados, a concentração de $\mathrm{K}$ foi superior no híbrido BR 205, diferente do que ocorreu em campo, onde, nas folhas, a concentração desse elemento foi mais elevada no BRS 2121.

As concentrações de cálcio (Ca) (Quadro 8), nas folhas e nas raízes, não variaram em função dos intervalos da irrigação, nos dois híbridos estudados. No colmo, entretanto, a concentração desse nutriente aumentou com o aumento nos intervalos entre irrigações. Em relação aos híbridos, o BR 205, com exceção de folhas, apresentou concentrações mais elevadas do nutriente.

A absorção de $\mathrm{Ca}$ parece ter sido tão comprometida quanto o crescimento. Esse nutriente, bastante imóvel no floema, depende inteiramente da corrente transpiratória para a sua absorção e translocação para as diversas partes da planta (Marschner 1995). Em experimento de casa-de-vegetação, Premachandra et al. (1992) observaram que a concentração de Ca no suco celular de folhas, em função da deficiência hídrica, diferiu entre os híbridos estudados. Esses autores consideraram o $\mathrm{Ca}$ um soluto osmótico importante em plantas de milho.

A concentração de $\mathrm{Mg}$ (Tabela 9) nas folhas do híbrido BRS 2121 foi superior na testemunha, a qual diferiu dos tratamentos T5 e T7, enquanto, no BR 205, a concentração desse nutriente não variou entre os tratamentos. No colmo e nas raízes, a concentração de $\mathrm{Mg}$ aumentou com o aumento no intervalo entre as irrigações, em ambos os híbridos. O híbrido BR 205 apresentou concentração mais elevada no colmo e valores semelhantes ao BRS 2121 em folhas e raízes.

A concentração foliar de $\mathrm{Mg}$, no híbrido BRS 2121, mostrou que houve maior efeito da deficiência hídrica na sua absorção do que sobre o acúmulo de massa seca nesses órgãos, o contrário do que ocorreu com a maioria dos nutrientes. Esse fato pode ser associado à competição desse cátion, principalmente com o 
TABELA 8. Concentração de potássio e cálcio em folhas, colmo e raiz de dois híbridos de milho submetidos a diferentes intervalos da irrigação.

\begin{tabular}{|c|c|c|c|c|c|c|c|}
\hline \multirow[b]{2}{*}{ Híbrido } & \multirow[b]{2}{*}{$\begin{array}{c}\text { Intervalo } \\
\text { irrigação } \\
\text { (dias) }\end{array}$} & \multicolumn{3}{|c|}{ K } & \multicolumn{3}{|c|}{$\mathrm{Ca}$} \\
\hline & & Folhas & Colmo & Raiz & Folhas & Colmo & Raiz \\
\hline & & & & & & & \\
\hline \multirow[t]{5}{*}{ BRS 2121} & 1 & $0,68 \mathrm{~A}$ & $0,51 \mathrm{~A}$ & $0,40 \mathrm{~A}$ & $0,53 \mathrm{~A}$ & $0,28 \mathrm{~A}$ & $0,59 \mathrm{~A}$ \\
\hline & 3 & $1,32 \mathrm{~B}$ & $0,74 \mathrm{AB}$ & $0,54 \mathrm{AB}$ & $0,43 \mathrm{~A}$ & $0,38 \mathrm{~B}$ & $0,67 \mathrm{~A}$ \\
\hline & 5 & $1,33 \mathrm{~B}$ & $0,96 \mathrm{BC}$ & $0,50 \mathrm{AB}$ & $0,43 \mathrm{~A}$ & $0,43 \mathrm{~B}$ & $0,54 \mathrm{~A}$ \\
\hline & 7 & $1,45 \mathrm{~B}$ & $1,29 \mathrm{C}$ & $0,59 \mathrm{~B}$ & $0,44 \mathrm{~A}$ & $0,43 \mathrm{~B}$ & $0,63 \mathrm{~A}$ \\
\hline & Média & $1,19 \mathrm{a}$ & $0,87 \mathrm{a}$ & $0,51 \mathrm{a}$ & $0,46 \mathrm{a}$ & $0,38 \mathrm{a}$ & $0,61 \mathrm{a}$ \\
\hline \multirow[t]{5}{*}{ BR 2121} & 1 & $0,99 \mathrm{~A}$ & $0,58 \mathrm{~A}$ & $0,38 \mathrm{~A}$ & $0,42 \mathrm{~A}$ & $0,34 \mathrm{~A}$ & $0,59 \mathrm{~A}$ \\
\hline & 3 & $1,18 \mathrm{~A}$ & $0,74 \mathrm{~A}$ & $0,50 \mathrm{AB}$ & $0,42 \mathrm{~A}$ & $0,35 \mathrm{~A}$ & $0,65 \mathrm{~A}$ \\
\hline & 5 & $1,63 \mathrm{~B}$ & $1,75 \mathrm{~B}$ & $0,66 \mathrm{~B}$ & $0,46 \mathrm{~A}$ & $0,52 \mathrm{~B}$ & $0,64 \mathrm{~A}$ \\
\hline & 7 & $1,57 \mathrm{~B}$ & $2,59 \mathrm{C}$ & $0,92 \mathrm{C}$ & $0,44 \mathrm{~A}$ & $0,63 \mathrm{C}$ & $0,80 \mathrm{~A}$ \\
\hline & Média & $8,91 * *$ & $76,72 * *$ & $11,74 * *$ & $0,61^{\mathrm{ns}}$ & $26,88 * *$ & $5,27 *$ \\
\hline Valor de "F" para $\mathrm{H}$ & & $8,91 * *$ & $76,72 * *$ & $11,74 * *$ & $0,61^{\mathrm{ns}}$ & $26,88 * *$ & $5,27 *$ \\
\hline Valor de "F" para I & & $39,46^{* *}$ & $105,51 * *$ & $22,85 * *$ & $0,72^{\mathrm{ns}}$ & $40,50 * *$ & $4,64 *$ \\
\hline Valor de "F" para H x I & & $4,58^{*}$ & $25,24 * *$ & $7,36 * *$ & $1,26^{\mathrm{ns}}$ & $9,76 * *$ & $2,99 *$ \\
\hline $\mathrm{CV}(\%)$ & & 11,0 & 15,3 & 16,0 & 16,5 & 10,7 & 12,2 \\
\hline
\end{tabular}

Médias seguidas de mesma letra maiúscula dentro de híbridos, e minúsculas entre híbridos não diferem entre si pelo teste Tukey $(\mathrm{p} \leq 0,05)$.

ns- não significativo; $*$ significativo a $5 \%$ de probabilidade; **significativo a $1 \%$ de probabilidade de erro

$\mathrm{K}$, nos sítios de troca das paredes celulares e, presumivelmente, também nos sítios de ligação da membrana plasmática (Marschner, 1995), levando à depressão na sua taxa de absorção.

A concentração foliar de S (Tabela 9) não diferiu entre os tratamentos, no híbrido BRS 2121. Entretanto, no BR 205, os intervalos de cinco e sete dias entre irrigações proporcionaram maiores concentrações do nutriente. No colmo, os teores de $\mathrm{S}$ foram mais elevados quando houve deficiência hídrica, em ambos os híbridos. Nas raízes, houve maior concentração de $\mathrm{S}$ nos tratamentos T5 e T7, para BRS 2121, e em T3 para BR 205. Semelhante ao que ocorreu em campo, o BR 205 apresentou concentrações mais elevadas de $\mathrm{S}$ em folhas e no colmo.

\section{Conclusões}

O parcelamento da adubação de cobertura de $\mathrm{N}$ e $\mathrm{K}$ não tem efeito sobre a concentração de macronutrientes nos híbridos BRS 2121 e BR 205, cultivados em campo.

A supressão da irrigação apresenta maior redução dos macronutrientes nos tecidos vegetativos, no híbrido BR 205, enquanto, no 
TABELA 9. Concentração de magnésio e enxofre em folhas, colmo e raízes de dois híbridos de milho submetidos a diferentes intervalos da irrigação.

\begin{tabular}{|c|c|c|c|c|c|c|c|}
\hline \multirow[b]{2}{*}{ Híbrido } & \multirow[b]{2}{*}{$\begin{array}{c}\text { Intervalo } \\
\text { irrigação } \\
\text { (dias) }\end{array}$} & \multicolumn{3}{|c|}{$\mathrm{N}$} & \multicolumn{3}{|c|}{$\mathrm{P}$} \\
\hline & & Folhas & Colmo & Raiz & Folhas & Colmo & Raiz \\
\hline & & & & & & & \\
\hline \multirow[t]{5}{*}{ BRS 2121} & 1 & $0,28 \mathrm{~A}$ & $0,18 \mathrm{~A}$ & $0,17 \mathrm{~A}$ & $0,07 \mathrm{~A}$ & $0,03 \mathrm{~A}$ & $0,19 \mathrm{~A}$ \\
\hline & 3 & $0,24 \mathrm{AB}$ & $0,24 \mathrm{~B}$ & $0,22 \mathrm{AB}$ & $0,08 \mathrm{~A}$ & $0,05 \mathrm{~B}$ & $0,22 \mathrm{AB}$ \\
\hline & 5 & $0,21 \mathrm{~B}$ & $0,24 \mathrm{~B}$ & $0,23 \mathrm{~B}$ & $0,08 \mathrm{~A}$ & $0,05 \mathrm{~B}$ & $0,26 \mathrm{C}$ \\
\hline & 7 & $0,22 \mathrm{~B}$ & $0,28 \mathrm{~B}$ & $0,25 \mathrm{~B}$ & $0,08 \mathrm{~A}$ & $0,05 \mathrm{~B}$ & $0,25 \mathrm{BC}$ \\
\hline & Média & $0,24 \mathrm{a}$ & $0,24 \mathrm{a}$ & $0,22 \mathrm{a}$ & $0,08 \mathrm{a}$ & $0,045 \mathrm{a}$ & $0,23 \mathrm{a}$ \\
\hline \multirow[t]{5}{*}{ BR 2121} & 1 & $0,24 \mathrm{~A}$ & $0,23 \mathrm{~A}$ & $0,20 \mathrm{~A}$ & $0,07 \mathrm{~A}$ & $0,03 \mathrm{~A}$ & $0,19 \mathrm{~A}$ \\
\hline & 3 & $0,23 \mathrm{~A}$ & $0,23 \mathrm{~A}$ & $0,21 \mathrm{~A}$ & $0,08 \mathrm{~A}$ & $0,04 \mathrm{~A}$ & $0,23 \mathrm{~B}$ \\
\hline & 5 & $0,23 \mathrm{~A}$ & $0,32 \mathrm{~B}$ & $0,24 \mathrm{AB}$ & $0,10 \mathrm{~B}$ & $0,06 \mathrm{~B}$ & $0,22 \mathrm{AB}$ \\
\hline & 7 & $0,21 \mathrm{~A}$ & $0,36 \mathrm{~B}$ & $0,29 \mathrm{~B}$ & $0,09 \mathrm{AB}$ & $0,07 \mathrm{~B}$ & $0,21 \mathrm{AB}$ \\
\hline & Média & $0,23 \mathrm{a}$ & $0,29 \mathrm{~b}$ & $0,23 \mathrm{a}$ & $0,085 \mathrm{~b}$ & $0,05 \mathrm{~b}$ & $0,21 \mathrm{~b}$ \\
\hline Valor de "F" para $\mathrm{H}$ & & $1,22 \mathrm{~ns}$ & $33,75 * *$ & $1,55 \mathrm{~ns}$ & $4,41 *$ & $15,12 * *$ & $5,33 *$ \\
\hline Valor de "F" para I & & $3,49^{*}$ & $24,79 * *$ & $6,79 * *$ & $4,41^{*}$ & $42,54 * *$ & $7,28 * *$ \\
\hline Valor de "F" para H x I & & $1,34 \mathrm{~ns}$ & $4,74 * *$ & $0,64 \mathrm{~ns}$ & $2,62 \mathrm{~ns}$ & $11,04 * *$ & $2,87 \mathrm{~ns}$ \\
\hline $\mathrm{CV}(\%)$ & & 11,0 & 15,3 & 16,0 & 16,5 & 10,7 & 12,2 \\
\hline
\end{tabular}

Médias seguidas de mesma letra maiúscula dentro de híbridos e minúscula entre híbridos não diferem entre si, pelo teste Tukey $(\mathrm{p} \leq 0,05)$.

ns- não significativo; * significativo a $5 \%$ de probabilidade; **significativo a $1 \%$ de probabilidade de erro.

BRS 2121, essa redução é maior nos grãos, indicando que, nesse híbrido, a deficiência hídrica afeta a translocação de nutrientes.

Em casa-de-vegetação, a deficiência hídrica afeta mais o crescimento do que a absorção de nutrientes, levando a maior concentração de $\mathrm{N}$ e $\mathrm{P}$ nos tecidos de ambos os híbridos estudados e de K e Mg no híbrido BR 205.

\section{Literatura Citada}

AKPORHONOR, E.E; EGWAIKHIDE, P.A.; ODILORA, C.A. Studies on the variation of macro nutrient level uptake of maize plants stem with age. Journal of Applied Science and Environmental Management, v.9, n.1, p.197-199, 2005.

BARBER, S.A.; OLSON, R.A. Fertilizer use of corner. In: DINAUER, R.C. (Ed.) Changing patterns in fertilizer use. Maddison: Soil Science Society of America, 1968. p.163-188.

BERGAMASCHI, H.; WHEELER, T.R.; CHALLINOR, A.J et al. Rendimento de milho e chuva em diferentes escalas espaço-temporais no sul do Brasil. Pesquisa Agropecuária Brasileira, v.42, n.5, p.603-613, 2007. 
CHAPIN, F. S. III. Effects of multiple environmental stresses on nutrient availability and use. In: MOONEY, H.A.; WINNER, W.E.; PELL, E.J. (eds.). Response of plants to multiple stresses. San Diego: Academic Press, 1991. p.67-88.

CUTLER, J.M.; RAINS, D.W. Effects of water stress and hardening on the internal water relations and osmotic constituents of cotton leaves. Physiologia Plantarum, v.42, p.251-268, 1978.

EMBRAPA. BR 2121 - Híbrido duplo alta qualidade protéica. Sete Lagoas: Embrapa Milho e Sorgo, 1997. (Folheto Informativo)

FERREIRA, V.M.; MAGALHÃES, P.C.; DURÃES, F.O.M. Produtividade de genótipos de milho (Zea mays L.) sob manejo diferenciado de irrigação e adubação. Ciência e Agrotecnologia, Lavras, v.24, n.3, p.663-670, 2000.

FLANNERY, R.L. Exigências nutricionais do milho em estudo de produtividade máxima. Informações Agronômicas, v.37, p.6-7, 1987.

FREDERICK, J.R.; BELOW, F.E.; HESKETH, J.D. Carbohydrate, nitrogen and dry matter accumulation and partitioning of maize hybrids under drought stress. Annals of Botany, v.66, n.4, p.407-415, 1990.

HEITHOLT, J.J.; JOHNSON, R.C.; FERRIS, D.M.; Stomatal limitation to carbon dioxide assimilation in nitrogen- and drought-stressed wheat. Crop Science, v.31, n.1, p.135-138, 1991.

HIROCE, R.; FURLANI, A.M. C.; LIMA, M. Extração de nutrientes na colheita por populações e híbridos de milho. Campinas: IAC, 1989. 24p. (Boletim Científico, 17).

ISLAM, A.K.M.S.; ASHER, C.J.; EDWARDS, D.G. Responses of plants to calcium concentration in flowing solution culture with chloride or sulphate as the counter-ion. Plant and Soil, v.98, n.3, p.377-395, 1987.

MARSCHNER, H. Mineral nutrition of higher plants. 2.ed. London: Academic Press, 1995. 889p.

MORGAN, J.M. Osmoregulation and water stress in higher plants. Annual Review of Plant Physiology, v.35, p.299-319, 1984.

PANOSO, L.A.; RAMOS, D.P.; BRANDÃO, M. Solos do campo experimental da Embrapa Milho e Sorgo: suas características e classificação no novo sistema brasileiro. Rio de Janeiro: Embrapa Solos, 2002. 92p. (Boletim de Pesquisa e Desenvolvimento, 5)

PITMAN, M.G. Ion uptake. In: PALEG, L.G.; ASPINALL, D. (eds.).The physiology and biochemistry of drought resistance in plants. Sydney: Academic Press. 1981, p.71-96.

PREMACHANDRA, G.S.; SANEOKA, H.; FUJITA, K.; OGATA, S. Water stress and potassium fertilization in field grown maize (Zea mays L.): effects on leaf water relations and leaf rolling. Journal of Agronomy and Crop Science, v.170, n.3, p.195-201, 1993.

PREMACHANDRA, G.S.; SANEOKA, H.; KANAYA, M.; OGATA, S. Responses of relative growth rate, water relations and solute accumulation to increasing water deficits in 
maize. Journal of Plant Physiology, v.135, p.257-260, 1989.

PREMACHANDRA, G.S.; SANEOKA, H.; FUJITA, K.; OGATA, S. Cell membrane stability and leaf water relations as affected by nitrogen nutrition under water stress in maize. Soil Science and Plant Nutrition, v.36, n.4, p.653-659, 1990.

PREMACHANDRA, G.S.; SANEOKA, H.; FUJITA, K.; OGATA, S. Osmotic adjustment and stomatal response to water deficits in maize. Journal of Experimental Botany, v.43, n.256, p.1451-1456, 1992.

SARRUGE, J.R; HAAQ, H.P. Análises químicas em plantas. Piracicaba: ESALQ, 1974. 122p.
SCHUSSLER, J.R.; WESTGATE, M.E. Maize kernel set at low water potential. I. sensitivity to reduced assimilates during early kernel growth. Crop Science, v.31, n.5, p.1189-1196, 1991 .

SCHUSSLER, J.R.; WESTGATE, M.E. Maize kernel set at low water potential. II. sensitivity to reduced assimilates at pollination. Crop Science, v.31, n.5, p.1197-1203, 1991b.

SCHUSSLER, J.R.; WESTGATE, M.E. Increasing assimilate reserves does not prevent kernel abortion at low water potential in maize. Crop Science, v.34, n.6, p.1569-1576, 1994.

WESTGATE, M.E. Water status and development of the maize endosperm and embryo during drought. Crop Science, v.34, n.1, p.76-83, 1994. 